\title{
Media Literacy for Visually Impaired : How it contributes for Peace and Breaking Stereotyping Visually Impaired
}

\section{Gulshan Gupta}

PhD Research Scholar, University School of Mass Communication, Guru Gobind Singh Indraprastha Unviersity, New Delhi, India Corresponding author: gpreit07@gmail.com

Received: 29 Jan., 2020

Revised: 17 Apr., 2020

Accepted: 23 May, 2020

\begin{abstract}
Media utilisation with competence by visually impaired would help them in two fronts. First is transformation of image stereotype of the community among normal population. Second, it would develop their capacities to take up many initiatives which were not thought before. Peace initiatives by them is one such area. Notwithstanding efforts of large number of individuals and groups in the society to contribute towards a culture of peace, it is critical that all sections of the society participate for peace. The study, in this context, aims to establish the importance of people with visual impairment to be part of peace building efforts. It also observed the role of being media literate in this connection. The study entailed focus group discussions with seven visually impaired persons and three expert interviews. The findings of the study have been categorically presented in the paper. It was observed during the focus group discussion that media literacy can be useful to shift persons with visual impairment from problem- oriented mindset to solution -orientation which is important to promote peace in the society.
\end{abstract}

Keywords: Media Literacy, Peace, Visually Impaired, Media Literacy for Peace

\author{
Peace is reverence for life. \\ Peace is the most precious possession of humanity. \\ Peace is more than the end of armed conflict. \\ Peace is a mode of behaviour.
}

Peace is a deep-rooted commitment to the principles of liberty, justice, equality and solidarity among all human beings.

Peace is also a harmonious partnership of humankind with the environment.

Today, on the eve of the twenty-first century, peace is within our reach.

- Yamoussoukro Declaration, 1989

Peace is a dynamic concept and involves constant engagement and initiatives on the part of individuals and the society at large. As a holistic concept, it entails both peace within oneself and peace in the outer society. In fact for peace to materialize in the society, it must start from inner peace, peace within the body, soul and mind. The Preamble to the Constitution of UNESCO aptly declares that; "since wars begin in the minds of men, it is in the minds of men that the defenses of peace must be constructed."

How to cite this article: Gupta, G. (2020). Media Literacy for Visually Impaired : How it contributes for Peace and Breaking Stereotyping Visually Impaired. Int. J. Peace, Edu. and Deve., 8(01): 41-47.

Source of Support: None; Conflict of Interest: None (9) 9 
With advancement of technology and proliferation of mass media and social media, media literacy skills have become critical. It is important for all sections of the society. If we have to negotiate the challenges in our societies, we need to acquire skills in media literacy and understand the functioning of the media. Notwithstanding the marginalization faced by persons with visual impairment in different aspects of their lives, it is important they are not excluded from acquiring media literacy skills. While many of them are able to access media with assistive technologies, most of them are not aware of the functioning of the media and how the messages are constructed by the media.

As history suggests, media plays a dual role- it can incite violence and can also play the role to bring communities together. Through such cohesive role, the media can contribute to the peace process. In this backdrop, it can be pointed out that by acquiring skills in media literacy, citizens can contribute to dialogues and initiatives towards peace.

It is in this context that this paper delves into how media literacy training can prove as solution to many problems for persons with visual impairment to bring peace in their daily lives. It also looks into how media literacy skills will enable them to contribute to peace and help in engaging in constructive dialogues.

S.S. Badrinath, world-famous ophthalmologist and founder of Sankara Nethralaya of Chennai opined, every third blind person in the world is an Indian. Persons with visual impairment face multiple challenges in their day-to-day lives. (Indian Express, 2014)

Visually impaired Radio Journalist, Mr. Danish Mahajan, (Secretary, Radio Udaan) considers media as a powerful channel that persons with visual impairment can use to spread their voice. He says, "We use different types of media i.e. social media, emails, radio etc. to communicate with huge audiences and we can count these skills as media literacy skills, which are necessary for us to be a global $21^{\text {st }}$ century citizen." One of the important benefits of being media literate which he feels is that it is a source of peace in the lives of people like him. He feels people with visual impairment who develop media literacy skills could contribute to dialogues in the society and would be able to construct meaningful messages which could contribute towards a cohesive society.

In this regard, Kundu (2018) stress on the need to implement media literacy programmes against violence that should be able to enhance open and true dialogue thereby facilitating mutual respect, tolerance, active listening skills, justice and equality. This will also help in promoting dialogue with self and between people from different cultures, creeds and faiths, he adds.

It is true that there is a vast difference between visually impaired people and sighted people in understanding the media world.

\section{Objectives of the Research}

1. To understand the scope, how media literacy can be introduced to persons with visual impairment.

2. To know how media literacy training can bring peace in the lives of persons with visual impairment.

3. To understand how empowerment in media literacy can help people with visual impairment to take up peace initiatives.

\section{Literature Review}

Underlining the importance of media literacy skills and use of advance technology in the $21^{\text {st }}$ century, UNESCO (2019) initiated a programme to promote media and information literacy (MIL) through communication practices for the cause of peace and social justice. MIL has been considered as an essential skill that enables people to acquire competencies to advocate and create their own counterbalance.

UNESCO (2006) also advocates for learning the use of advance technology to develop literacy skills for achieving the goals of sustainable development and ensuring peace and also working on how information communication technology (ICT) can contribute to increasing access to literacy and improving the quality of literacy education. 
Media Literacy for Visually Impaired : How it contributes for Peace... 줄페

Meanwhile, when we talk about the persons with visual impairment, it becomes more challenging to introduce media literacy with the combination of technological advancement in the digital age. It is true that digitalization helps visually impaired people to confront the daily challenges and difficulties in life but it requires more attention to enhance their technological knowledge. As the study shows a less focus is being given to disabled people in the aspect of media literacy (Weigand $\mathrm{M}$. et al. 2013).

Candido (2008) argues in her research that there is a lot to be done to know and experience the perspectives and views of visually challenged persons about online learning. To achieve this objective she supports qualitative methods to identify the challenges being faced by the people with visual impairment towards digital learning.

Over the past 15 years, there has been a grand shift in the technology and nature of media content and its uses. Media literacy would require the development of the ability to think critically and independently and take decisions regarding action. The stages by which such development would take place were identified as 'developing the ability to listen with attention, speak with clarity, read with understanding, think with independence and write with confidence and conviction (Ghosh, A. 2006).

A study discusses that developing media literacy skills can be one of the perspectives to engage youth in the activities promoting peace in the society. In this context of persons with visual impairment it is crucial to empower them, to strengthen their capacities and ensure they understand the importance of their civic engagement and use of different communication tools to implement innovative actions for a culture of peace. A study shows that a literate person was familiar with high culture; those marked as literate are well read in what usually consists of selected canonical works of literature and they had the ability to write polite, proper and polished essays (Frechette, 2002).

Media can also promote peace, tolerance and dialogue between cultures, people, religious and political groups. In that sense media can encourage knowledge and respect among nations or cultures in order to avoid conflicts (Berger, 2015).

\section{RESEARCH METHODOLOGY}

\section{Focus Group Discussion}

The focus group discussion is a method engaging a small group of respondents to capture their responses and understand their views, related to the research (Hennink, M.M. 2007). FGD was conducted with visually impaired young people of Saksham. Saksham i.e. Samrdrushti Kshamata Vikas Evam Anusandhan Mandal is a charitable national organization working for persons with disabilities especially dedicated to the service of visually impaired.

\section{Expert Interviews}

Expert interview is a method to collect the primary information on the subject of the research. In-depth interview with experts was conducted with the help of open-ended questionnaire. Using open-ended questionnaire usually save time and resources and allow the subjects to answer in any way they wish (Wimmer and Dominick, 2011).

\section{Sampling}

Convenient sampling was used for the selection of respondents of focus group discussion. Convenient sampling can be used to collect information from easily accessible sources. In convenient sampling subjective methods are used to decide which elements should be included in the sample (Lavrakas, 2008).

The in-depth interviews were conducted after selecting three visually impaired experts with relevant knowledge employing purposive sampling technique. It is a qualitative research method for the selection of experts (Patton, 2002). Dr. Dayal Singh Panwar (Professor at Shri Lal Bahadur Shastri National Sanskrit University, Delhi), Mr. Harish Gulati (Principal of Government School, Delhi) and Mr. Danish Mahajan, (General Secretary, Radio Udaan) were interviewed. 


\section{Presentation of Findings}

The findings are based on the responses received from focus group discussion and inputs from experts. In the focus group discussion (FGD) we categorically discussed different forms of media and came to know how media literacy education can bring peace in the lives of persons with visual impairment. Also we gauged how the enhanced communicative abilities can help people with visual impairment to take up peace initiatives.

\section{Radio}

For Radio, discussion with Radio Udaan officials was conducted. Radio Udaan is an online radio run by persons with visual impairment.

There are many radio channels which are run by persons with disabilities. Radio Udaan is among one of them. It was launched in the year 2014 and successfully being run by an enthusiastic team of visually challenged Radio Jockeys. They are developing and broadcasting all types of programs for audience. Five to six shows, dedicated to disability in a week presented by specially-abled people. All the team members are from different parts of the country, all are disabled, maximum of them are visually impaired.

Mr. Danish Mahajan, General Secretary of Radio Udaan shared his views about their programmes. He says "Our station runs 24 hours and 7 days a week. Our radio station reflects the communities we serve. We don't just offer content to our listeners but we also take queries and help our listeners lead a happy, satisfied and poised life. Our RJs record their shows at their home place; share the recorded show through draw box. We broadcast the show on the scheduled time and later, we upload these shows on our YouTube channel too. I have conducted more than 500 expert interviews and broadcasted on Radio Udaan. We are also organizing an 'Udaan Idol' for disabled people". They broadcast their shows based on different themes like education and technology, which offer knowledge and messages of harmony, peace and cultural values. Through the platform, they create awareness among people about the policies of government, the rights, latest schemes, incredible India and every such deed that comes to their notice.

Udaan gives people with disabilities a chance to participate so that they can come up and present their opinions, views and participate in different shows. Whether games, quizzes, entertainment, education or personality development, the station has it all for everyone.

An exciting thing about the is that it knows listeners' need. Danish said, "We come from different backgrounds and understand the aspirations and desires of our listeners. We give them the freedom to talk to us and become a part of Radio Udaan Family. We not just want to become a supplier of entertainment and knowledge to our listeners but we want to become a part of their day to day life, family and lifestyle. We Run a Udaan Idol contest every year for persons with disabilities. There is no other platform which is dedicated to identify the talent inside the persons with disabilities. Through Udaan Idol, we give opportunities to them." Danish says, "this is how we try to spread the peace vibrations through the society. Peace is not something which is tangible. It is an intangible component which can be served and received through these little efforts, in which we are indulging. And through media literacy education it may be possible for other persons with visual impairment to spread their voice by using different media tools."

The capability of understanding media messages varies from person to person based on their education, social environment and other circumstances and the same applies for visually impaired people too.

Mr. Danish suggests that there are so many problems and challenges in the society; we need to provide solutions by identifying them. For example, if a tourist lost his luggage and money in a taxi and if our Radio Jockey could help him/ her to get back the lost luggage and money by a radio announcement, it will be a great help for the tourists. It is also a contribution of a media literate person to build a peaceful society. 


\section{Digital Media}

Instead of traditional media like newspapers and television, persons with visual impairment find digital platforms more accessible and friendly. Frau-Meigs (2014) advanced the term Augmented MIL, which includes a focus on digital competencies and internet issues to be given more prominence in MIL. LohoChoudhury, Mitra \& Bhattacharya (2015) observed that the pragmatics of literacy has shifted from mere ability of three Rs to that of ability to manipulate resources of digital environment. Any question of harnessing literacy for utilizing information technology across spectrum leads us to consider qualitative transformation accompanying informatics. But persons with visual impairment face the threat of security when they use different online digital platforms with the help of internet. People with visual impairment ask a question that 'to what extent they have to be mindful and digital literate'. They are still struggling to connect with the digital society.

Dr. Dayal Singh Panwar is visually impaired and President of Samrdrushti Kshamata Vikas Evam Anusandhan Mandal (SAKSHAM). He opines, " media literacy (ML) education can play an important role to minimize hazards and threats of digital media. ML competencies can be learned which will help to overcome from challenges of digital platforms and expanding possibilities for them to achieve their full potential."

For example, he says that through digital media platforms, "I usually give my all lectures and presentations in seminars and conferences, and even we are also organizing national and international webinars through different online meeting platforms". In the context of media literacy education to persons with visual impairment, he says that digitalization has forced everyone to be digitally literate. It will be more effective, if we could have a media literacy module specially focused on the need of visually challenged people. We also need teachers who could teach the module.

People involved in digitalization and technological development should understand that for a visually impaired person, it is not always easy to be an efficient user of digital mediums. They always bear threat of phishing attempts from fake Ids and unbelievable news from malware sources. A single unfortunate act on digital platform will put negative impact on them. Therefore, developing digital literacy skills is one of the approaches to empower (Torrent, 2013) them to use their knowledge to reach out to people to make a peaceful society and to understand their role as active citizen.

Dr. Panwar says, "when we see at the international level, there are number of visually impaired individuals, who are trained and skilled enough to make videos on different issues and run their own YouTube channels. They get thousands of likes on their videos and also earn money through it. They share their own stories and promote others who are blind and doing remarkable work silently. There is a Youtube channel Blind to Billionaire working on the same pattern. It is an example of how a person, who is facing blindness, can live a peaceful life and also contribute for building a peaceful society by being a media literate."

\section{Social Media}

Social media is a platform where individuals can form groups and become friends to connect with each other in virtual world. There are so many social media sites available like Facebook, Instagram, Twitter, WhatsApp, LinkedIn etc. but for visually impaired persons, not all the social media sites are equally accessible. According to the participants of FGD, most of them use WhatsApp and Facebook. WhatsApp is the platform which is manageable and accessible to all of them. Many participants are having Facebook Id, but they are not active user of it. They do only like the posts of others while only few of them update their posts daily or weekly. Facebook and WhatsApp both can be used on Smartphones and laptops. Mostly visually impaired people are using mobile version of these applications. But still Facebook is more accessible and useful for us than any other social media network, one participant opined.

Another participant said that other social media platforms like Twitter and Instagram are difficult 
to use. For example, on Instagram, the available content is in form of image and photos which is not accessible to them, similarly in Twitter they cannot navigate the accurate option to access the content. Both of these platforms are having tough navigation.

One respondent opined that it seems that these platforms have not been designed for the use of persons with visual impairment. The concept of inclusive development is still unreachable. The issue of digital inclusion - be it websites, technology, information and media, which is equally critical, has not found much traction (Dorodi Sharma 2017).

Even mainstream media does not discuss the disability issues in a broad way because there is no TRP in it. That's why maximum time they share disability related issues whenever they get a chance and platform. Social media plays vital role in spreading message and voice of disabled community. In newspapers, people writing articles on disability lack in research. Many facts in those articles seem vague.

Dr. Panwar says, " by only using mainstream media, you limit your understanding about the world. In order to get the most accurate information, use diverse sources of independent media and develop critical thinking skills. Social media is among one of those platforms. If persons with visual impairment could improve their social media skills, it is quite certain that the strength of their expression and self presentation will help to communicate the messages of peace in the society. It will become an opportunity for them for self-introspection through which they can generate peaceful thoughts to share with the outer world."

People with visual disability can harmonize the tools of new media like Facebook, Twitter, Youtube, Instagram, Whatsapp etc, by communicating their own stories of peace initiatives. New media devices can help to present and spread the information in dynamic way. For example, there is a group of visually challenged people on Whatsapp, where a person from Rajasthan, send daily news in the form of audio, so that visually impaired people could also know the morning news at the same time when a sighted person reading a newspaper in morning with a cup of tea. Social media can enable visually disabled people to engage in their own initiatives for peace and also for interactive dialogues.

For example, a visually impaired engineer from Facebook has developed a technology 'automatic alternative text' for persons with visual impairment to generate a description of a photo through object recognition technology. For example, a group photo on the beach, a person using a screen reader on iOS would hear: "This image may contain: Three people, smiling, outdoors" (Facebook Accessiblity, 4 April, 2019).

\section{Blogging}

Nowadays, writing for blogs has also become a mode of communication. There are many examples of persons with visual impairment writing blogs and sharing their views and stories. An IT expert in interview said, "I am writing blogs from long time. People living in rural periphery are more cut off from this world. Young generation is trying to be connecting with other disabled persons through different social media platforms, blogging being one of them." (Focus Group Discussion with IT Students AICB, Delhi).

He said, "we express our personal experiences, how a visually impaired see the world and what are the solutions we find to counter the challenges. We use all digital and internet based facilities. We book cab for our own. We are writing articles in newspapers. Being a visually impaired we are continuously and constantly working for the disabled community, giving computer training to uneducated and needy people having vision impairment. It helps visually impaired to become a media literate."

During the discussion with focus group, it was observed that most of the participants were not keen to write blogs. For them, writing is an intellectual job which they don't find entertaining.

But, researcher's study and field experience says that there are many visually impaired people writing regular blogs having thousands of readers and followers. 
During the present study, the researcher found a website blog 'life of a blind girl' owned by a visually impaired girl named Holly from Yorkshire. She is a regular blogger writing on different themes related to disability, assistive technology, mobility, accessibility etc. By visiting her blog, it can be observed that it is a resourceful website where persons with visual impairment can find the information about new innovations in the field of assistive technologies. For her continuous writing she has won the Social Media Influencer Award for the year 2019. It is example of a media literate individual trying to strengthen the relationships and promoting the peaceful environment among the community of persons with different disability.

\section{CONCLUSION}

This study tries to capture the words of experts and participants of focus group discussion who are actively using different platforms of media with the advance knowledge of technology. The data collected is significant in terms of identifying the scope of media literacy training among persons with visual impairment for facilitating peaceful environment in the technologically driven media in all sectors of life. It can be analyzed through the experts' comments and findings of focus group discussion that if visually impaired persons are competent in media literacy skills, they are more independent, solution oriented, keep themselves well informed, and their societal contribution is more constructive.

They take new initiatives with focused goals which later have been converted in peace initiatives like Radio Udaan, presently contributing for the better of the society.

There are many dedicated agencies, working for the development of the persons with different disabilities. This study shows that skilling in media literacy can transform stereotype portrayal of persons with visual impairment (and other disabilities) to independent valuable contributor to the democratic society. But this is only possible, when they themselves will take initiatives to change this image. Their different efforts by educating them in media literacy will open the door of new dimensions how collectively peace factor can be placed in the life of all visually impaired people.

\section{REFERENCES}

Barrett, M. 2015. Film Literacy- the power of Images. Retrieved from https://www.teachermagazine.com.au/articles/filmliteracy-the-power-of-images.

Berger, G. 2015. 'Media in Support of Sustainable Development and a Culture of Peace'. UNESCO (2015).

Choudhury, L., Mitra and Bhattacharya. 2015. Three-Tier New Media Literacy for Realizing Full Communication Potential in Information Society. New Directions in Media: IIM Critical Practitioner Series Edited by Islam \& Roy, Bloomsbury. New Delhi.

Frechette, J.D. 2002. Developing media literacy in cyberspace. Pedagogy and critical learning for the twenty-first-century classroom. Westport, Connecticut, London: Praeger.

Ghosh, A. 2006. Use of Communication for Literacy and Empowerment: Communication Technology and Human Development. New Delhi: Sage Publications, pp. 81-146.

Kundu, V. 2018. Enhancing Learning on Peace and Nonviolence through Media Literacy: The Case for a Nonviolent Media Literacy Programme. MILID Yearbook 2018/2019. Edited by Tornero, Orozco and Hamberger, Published by UNESCO Chair on Media and Information Literacy for Quality Journalism Faculty of Communication Sciences, Autonomous University of Barcelona (UAB) 08193 Bellaterra, Barcelona.

Sharma, D. 2017. The Wire, Why does mainstream Indian discourse on Digital inclusion leave out disability; 09 May, 2017 Retrieved from https://hewire.in/133489/mainstreamindian-discourse-digital-inclusion-leave-disability/

Tornero, J.M. Perez and Varis, T. 2010. Media Literacy and New Humanism; UNESCO Institute for Information Technologies in Education.

Torrent, J. 2013. 'Media and Information Literacy: Fostering Intercultural Dialogue and Sustainable Development' in Ulla Carlsson and Sherri Hope Culver (eds). Media and Information Literacy and Intercultural Dialogue. MILID Yearbook 2013. The International Clearinghouse on Children, Youth and Media.

Understanding Media and Information Literacy (MIL) in the Digital Age: A Question of Democracy. Edited by Ulla Carlsson. UNESCO. 2019. Retrieved from https://en.unesco.org/sites/default/files/gmw2019_ understanding_mil_ulla_carlsson.pdf

Using ICT to Develop Literacy. UNESCO. 2006. Edited by Ellie Meleisea. Retrieved from https://unesdoc.unesco. org/ark:/48223/pf0000146426/PDF/146426eng.pdf.multi

Weigand, M. et al. 2013. Media Competencies in the context of Visually Impaired People, pp. 190-197. 
